\title{
ANTONIO DE LAS VIÑAS Y LOS PÉREZ DE GUZMÁN. SOBRE LA "EJECUCIÓN Y PINTURAS DE CIERTOS LUGARES DE ESPAÑA" EN 1567: ¿LAS VISTAS DE TARIFA, ZAHARA DE LOS ATUNES Y SANLÚCAR DE BARRAMEDA?
}

\author{
FERNANDO CRUZ ISIDORO \\ Universidad de Sevilla
}

\begin{abstract}
Documentamos la libranza de 50 ducados en 1567 del VII duque de Medina Sidonia, Don Alonso Pérez de Guzmán, a instancias de su tío Don Pedro Pérez de Guzmán, I conde de Olivares, al pintor Antonio de las Viñas, para la realización de ciertas vistas de lugares de España, que podrían ser las de Tarifa, Zahara de los Atunes y Sanlúcar de Barrameda, pues formaban parte de su señorío y están fechadas ese año.

Palabras clave: Antonio de las Viñas; Pérez de Guzmán; Anton Van den Wyngaerde; Casa ducal Medina Sidonia; Vistas topográficas andaluzas.
\end{abstract}

ANTONIO DE LAS VIÑAS \& THE PÉREZ DE GUZMÁN. ON "PAINTINGS OF CERTAIN PLACES IN SPAIN" IN 1657: THE VIEWS OF TARIFA, ZAHARA DE LOS ATUNES \& SANLÚCAR DE BARRAMEDA?

This article documents the payment in 1567 of 50 ducats by the VII Duke of Medina Sidonia, Don Alonso Perez de Guzman, at the request his uncle Don Pedro Perez de Guzman, I Count of Olivares, to the painter Antonio de las Viñas for having made certain views of places in Spain, which could be those of Tarifa, Zahara and Sanlucar de Barrameda, as they were part of his domains and these works are dated that year.

Key words: Antonio de las Viñas; Pérez de Guzmán; Anton Van den Wyngaerde; Medina Sidonia Ducal house; Views of Andalusia.

Mucho se ha escrito sobre la producción artística de Wyngaerde desde que su vista del Alcázar madrileño se reprodujera por Carl Justi a finales del siglo XIX, y la serie de dibujos de lugares se diera a conocer como colección por Haverkamp-Begemann en 1969, poniéndola en valor, aunque su mayor difusión se debió a la magnífica edición dirigida por Richard L. Kagan en 1986, al reproducir cada una de ellas con gran calidad y completarlas con estudios específicos, lo que dio lugar a una segunda edición corregida y aumentada veintidós años más tarde, en 2008. A esa labor inicial se han sumado diversos autores, que han tratado su obra desde distintos puntos de vista, como las representaciones de escenas de guerra, con la conquista del Peñón de Vélez de la Gomera o la guerra de San Quintín ${ }^{1}$, los viajeros del siglo XVI y las representaciones de ciuda-

1 Galera I Monegal, 1998. Bustamante García, 2006: 169-177. Cabañas Bravo; López-Yarto Elizalde; RinCÓN GARCÍA, 2008, pp. 169-177. 
des $^{2}$, o estudios específicos de urbanismo y patrimonio de diversas ciudades a través de las vistas representadas $^{3}$, por lo que no tiene cabida en esta breve aportación el anotar exhaustivamente la abundante bibliografía al respecto, y sólo exponer la nueva documentación localizada que pueda resultar de interés para su mejor conocimiento.

Nacido probablemente en Bruselas hacia 1525, su trayectoria profesional, como dibujante especializado en vistas urbanas, resulta bien conocida desde 1544, en un circuito profesional que le llevó de los Países Bajos a Francia, Italia, Inglaterra y finalmente a España, donde permaneció desde 1562 hasta su fallecimiento, acaecido en Madrid el 7 de mayo de 1571. Al servicio de Felipe II desde 1557, ocupó un papel relevante, como lo demuestra su obra conservada y el prestigio que alcanzó, en la corte artística creada por un monarca con grandes conocimientos de arquitectura, como afirman, entre otros, Jonathan Brown o Kagan ${ }^{4}$, que mantienen la hipótesis del gusto filipino por las representaciones topográficas de las principales ciudades de sus reinos como reflejo del triunfo de la corona hispana. Viajero impenitente, es bien conocido su itinerario geográfico por España: en 1563 por las tierras de la Corona de Aragón; en 1564 lo encontramos en Málaga para dibujar, por encargo real, el asedio al peñón de Vélez de la Gomera; en 1565 de regreso en la Corte para pintar tramoyas y acompañar a la reina Isabel de Valois a Medina del Campo y Burgos; en 1567 recorre Andalucía; o, poco antes de su muerte, en 1570, de nuevo paseando por Castilla. De todos esos lugares realizó bocetos de monumentos concretos, estudios de localización y dibujos preparatorios, que luego utilizó para la confección de las "vistas" de ciudades y pueblos hispanos que se conservan en tres colecciones extranjeras (National-Bibliothek de Viena, el Victoria and Albert Museum de Londres, y en el Ashmolean Museum de Oxford), con las que logra un auténtico inventario topográfico de las principales urbes de los reinos ibéricos. Felipe II, aparte de sufragar su realización, le allanó dificultades facilitando su viaje, como con la Real Orden de 8 de agosto de 1570, al ordenar proporcionarle todo lo que fuese necesario para "pintar la descripción de algunos dessos pueblos principales" suponer que con el mismo motivo existieron con antelación reiterados documentos, y al hilo de esa hipótesis, traemos a colación una aportación documental inédita, que aclara cómo en su viaje por Andalucía, recibió la ayuda de la poderosa familia de los Pérez de Guzmán, reflejo del deseo real.

A instancias del I Conde de Olivares, D. Pedro de Guzmán, su sobrino-nieto, el joven VII duque de Medina Sidonia, D. Alonso Pérez de Guzmán, desde su palacio en Sanlúcar de Barrameda, que era la capital de su amplio estado territorial, ordenó librar en mano el 16 de abril de 1567 "a Antonio de las Viñas, pintor de Su Magestad", la cantidad de 50 ducados en reales, que hacían 550, para "la (ejecu)çión y pinturas de ciertos lugares de España que a de pintar"6. D. Alonso, hijo del conde de Niebla D. Juan Claros de Guzmán (que falleció antes de ser duque), y nieto del VI duque de Medina Sidonia D. Juan Alonso Pérez de Guzmán, contaba en aquellos momentos sólo 18 años, pues había nacido en 1549, por lo que todavía se hallaba en minoría de edad y bajo tutela de su enérgica e inteligente madre, la condesa D. ${ }^{a}$ Leonor Manrique de Sotomayor y Zúñiga, que manejaba las finanzas de la Casa con suma perspicacia y austeridad, que debió consentir esa importante libranza.

Pero la ocasión lo merecía, pues era un encargo que procedía del mismo rey, como le comunicó por carta su tío-abuelo "el señor Conde de Olivares", que aunque formaba parte de la rama

\footnotetext{
${ }^{2}$ Cabañas Bravo; López-Yarto Elizalde; Rincón García, 2011, pp. 281-294

3 Entre otros, SÁnchez NúÑEZ, 1996: s./p. IbáÑEZ Martínez, 2003: 71-77. CABallero SÁnChez, 2008: 109-147. GÁmIz Gordo, 2011, pp. 74-79.

${ }^{4}$ Véase Felipe II, un monarca y su época. Un príncipe del Renacimiento, 1998. KaGAN, 2008: 14-39.

5 Kagan, 2008: 11-13, 40-53. Haverkamp-Begemann, 1988: 54-57.

${ }^{6}$ Archivo Fundación Casa Medina Sidonia leg. 2.570 fol. 127 vto.
}

Arch. esp. arte, LXXXVII, 346, ABRIL-JUNIO 2014, 163-170 ISSN: 0004-0428, eISSN: 1988-8511, doi: 10.3989/aearte.2014.12 
menor de la familia, asentada en El Aljarafe sevillano, ocupaba, no obstante, un papel relevante en los asuntos de la Corte. El ascendiente que sobre él tenía Pedro de Guzmán debía ser importante, pues dos años más tarde, en 1569, lo representó en su casamiento por palabras de futuro con la menor D. ${ }^{a}$ Ana de Silva y Mendoza, hija de la Princesa de Éboli, cuando la niña contaba sólo 5 años, con la que llegaría a tener una prolífica descendencia ${ }^{7}$. D. Alonso no pudo gobernar su Estado con total libertad hasta alcanzar la mayoría de edad el 5 de septiembre de 1570, que determinó que su madre se retirase al palacio que construyó en el interior del convento dominico sanluqueño de Madre de Dios, cuya iglesia, claustro y otras dependencias había costeado ${ }^{8}$. A partir de esos momentos, el papel político que le fue asignado por el monarca fue acrecentándose, sobre todo en Andalucía occidental, pues si ya en 1581 fue nombrado Gobernador del Estado de Milán y Capitán General de la Lombardía, desde 1588 ostentó los cargos de Capitán General de la Costa de Andalucía y Capitán General del Mar Océano, teniendo a su cargo todo lo referente a la defensa de la costa andaluza y los asuntos del Norte de África, más la importante misión del apresto de la flota de Indias, que se efectuaba en el puerto de Bonanza de su ciudad de Sanlúcar, para finalmente ser nombrado miembro de los Consejos de Estado y Guerra y, muy a su pesar, General de la Invencible con la que el monarca quiso domeñar Inglaterra ${ }^{9}$.

Es de suponer que el apoyo económico de los Pérez de Guzmán se reflejase esencialmente en la ejecución de los apuntes y dibujos fechados en 1567, que llevó al pintor a cruzar buena parte de Andalucía, costeándole parte del viaje. Y como no podía ser menos, varias de las "vistas" recogen ciudades y lugares pertenecientes o vinculados a la Casa ducal, esenciales en el mantenimiento económico y "mítico" de su poderío. Al parecer, empezó el viaje en Córdoba, la primera de las vistas conservada y fechada ese año, continuando con Úbeda-Baeza (boceto inacabado), Jaén (fechado), Granada (fechado), Alhama de Granada (realizado de camino entre Granada y Cádiz), Antequera (fechado), la costa de África, Ojén, Gibraltar (fechado), Tarifa, Zahara de los Atunes, Cádiz (fechado), El Puerto de Santa María (fechado), Jerez (fechado), Sanlúcar (fechado), Sevilla, Itálica, Carmona (fechado), para continuar por Extremadura, con vistas de Mérida, Guadalupe (fechado) y acabar en Ciudad Real con la de Talavera de la Reina (fechado) ${ }^{10}$.

En el documento contable parece quedar claro que parte de las vistas todavía no se habían realizado, como se desprende de la expresión "que a de pintar", y de que sean las citadas parece lógico, puesto que la mayoría de ellas aparecen firmadas y fechadas ese año de 1567.

\footnotetext{
${ }^{7}$ El anciano D. Pedro fue hijo del III duque de Medina Sidonia D. Juan de Guzmán y de D. a Leonor de Guzmán, hija del conde de Plasencia, y vino al mundo, al parecer, el 29 de junio de 1504 en Sanlúcar, aunque otros señalan su nacimiento en Sevilla. Fue hermano del V duque de Medina Sidonia D. Alonso, llamado el Fatuo por su anormalidad, y del VI duque D. Juan Alonso, por lo tanto un tercerón, que no hubiese alcanzado ninguna posición familiar de no habérsela ganado a pulso en un largo historial de servicios a la monarquía hispana, primero a las órdenes del emperador Carlos V en la insurrección comunera de Sevilla, y en múltiples circunstancias en Alemania, Flandes, Austria y Túnez, que le valió la autorización, el 15 de octubre de 1535 en Palermo, para fundar un mayorazgo, y con ello su propia Casa y Estado, en torno a la villa aljarafeña de Olivares, con el título de conde, para luego continuar prestando servicios a Felipe II. A pesar de residir en Madrid y de sus muchas obligaciones, tuvo casas en Sevilla y construyó palacio en Olivares, que a la postre fue el centro de sus propiedades territoriales, manteniendo un constante interés por los temas andaluces y los que afectaban a su familia, cuya rama principal residía en Sanlúcar de Barrameda, capital de los Estados de los Pérez de Guzmán, donde él mismo también tuvo vivienda, en la cuesta llamada de Almonte, mirando hacia la antigua calle del Chorrillo (parte baja de la actual Ganado), recibiendo en sus primeros años una ayuda de costa de sus hermanos de 650.000 maravedíes anuales, que salían de las arcas ducales. VelázQuez Gaztelu, 1996: 228.

8 Véase sobre el mecenazgo artístico de esta señora: CRUZ IsIDORO, 2010: 131-164; 2011: 79-106.

9 Álvarez de Toledo, 1994: 21, 37.

10 Wyngaerde había estado años atrás en Andalucía, cuando en 1564 realizó las vistas de Málaga, el Peñón de Vélez de la Gomera y Melilla. KAGAN, 2008: 254-352
}

Arch. esp. arte, LXXXVII, 346, ABRIL-JUNIO 2014, 163-170

ISSN: 0004-0428, eISSN: 1988-8511, doi: 10.3989/aearte.2014.12 


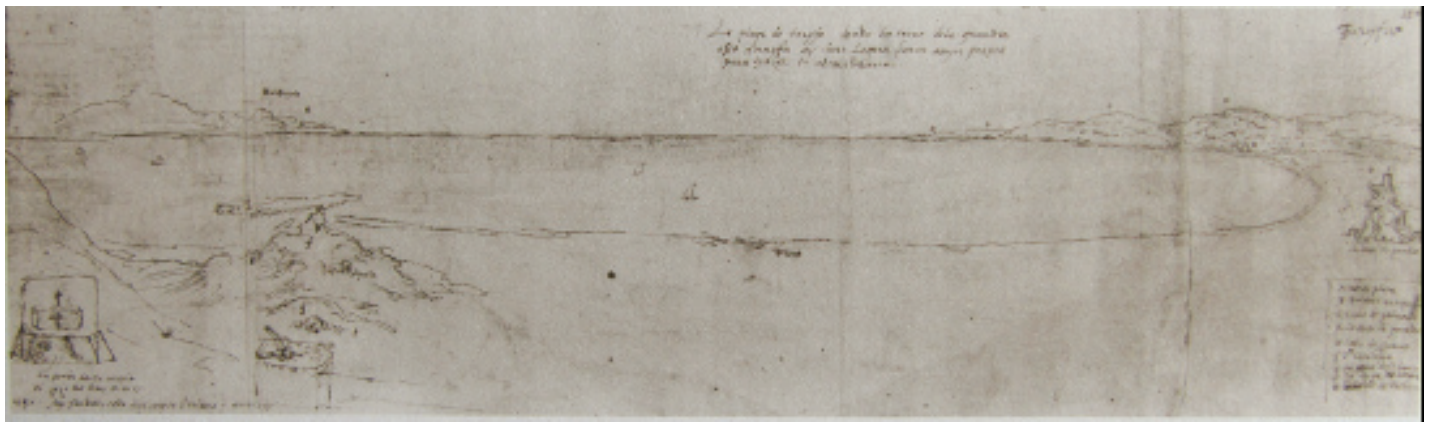

Fig. 1. Apunte pequeño de la bahía y playa de Tarifa, National-Bibliothek de Viena fol. 33 vto.

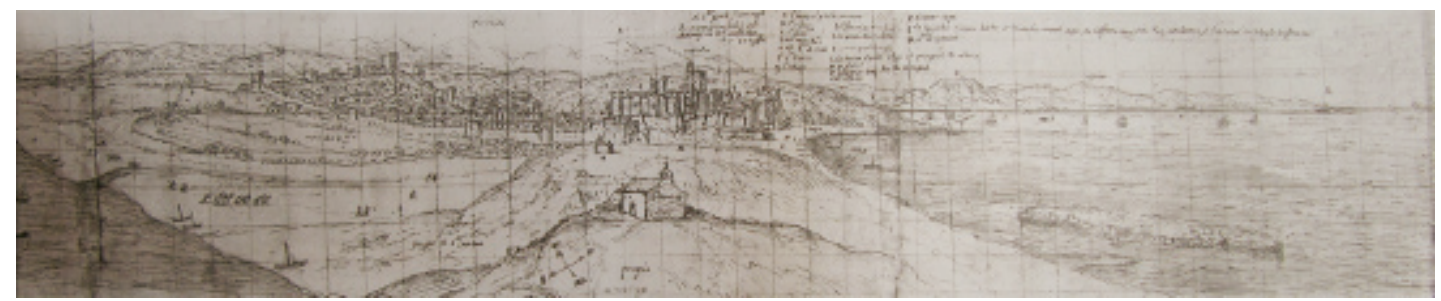

Fig. 2. Tarifa, National-Bibliothek de Viena fol. 33 ro.

También se puede colegir, que a la hora de la libranza ducal, efectuada el 16 de abril, el artista flamenco se encontraba en Sanlúcar, pues se anota que mostró carta de pago para hacerla efectiva, lo que permite fechar el entorno de la vista que recoge esa ciudad que no estaba datada. En cuanto a la cuantiosa suma de 550 reales, resulta interesante este descargo ducal si lo comparamos con encargos artísticos realizados por D. Alonso por esos años, como en 1575 al afamado escultor castellano Juan Bautista Vázquez "el Viejo", pues por la hechura, policromía y dorado de las imágenes de bulto redondo de un Cristo atado a la columna y un San Pedro, de tamaño menor que el natural, para la capilla de su palacio sanluqueño, se le libró una cantidad sensiblemente menor, 400 reales, y al vanguardista Gaspar Núñez Delgado, oficial en el taller del anterior, sólo 180 por una pareja de Santos Juanes y un paso de Ntro. Sr. con la cruz a cuestas para el palacio de la familia en Sevilla, una pieza de valía, que no ha podido todavía identificarse si es que se conserva, que sería, sin dudar, un valioso antecedente del afamado nazareno conocido como Señor del Gran Poder ${ }^{11}$.

El reconocimiento de Wyngaerde por la munificencia del VII duque quedaría de manifiesto con la representación visual de tres de sus ciudades, Tarifa (de la que se conservan tres dibujos en la colección de Viena: un apunte pequeño de la bahía, fol. 33 vto. (fig. 1); la vista casi acabada del fol. 64; y la terminada del 33 ro. (fig. 2); Zahara de los Atunes (con dos dibujos en la colección de Viena: un apunte de la pesca y secado de atunes, fol. 33 vto. (fig. 3); y la que recoge el poblado, fol. 74 (fig. 4); y la propia capital del estado ducal, Sanlúcar de Barrameda (en la colección de Oxford C.III 259) (fig. 5). Sin dudar, de las tres, es esta última ciudad la más importante para

11 CRuz IsIdoro, 2012: 282-283. 


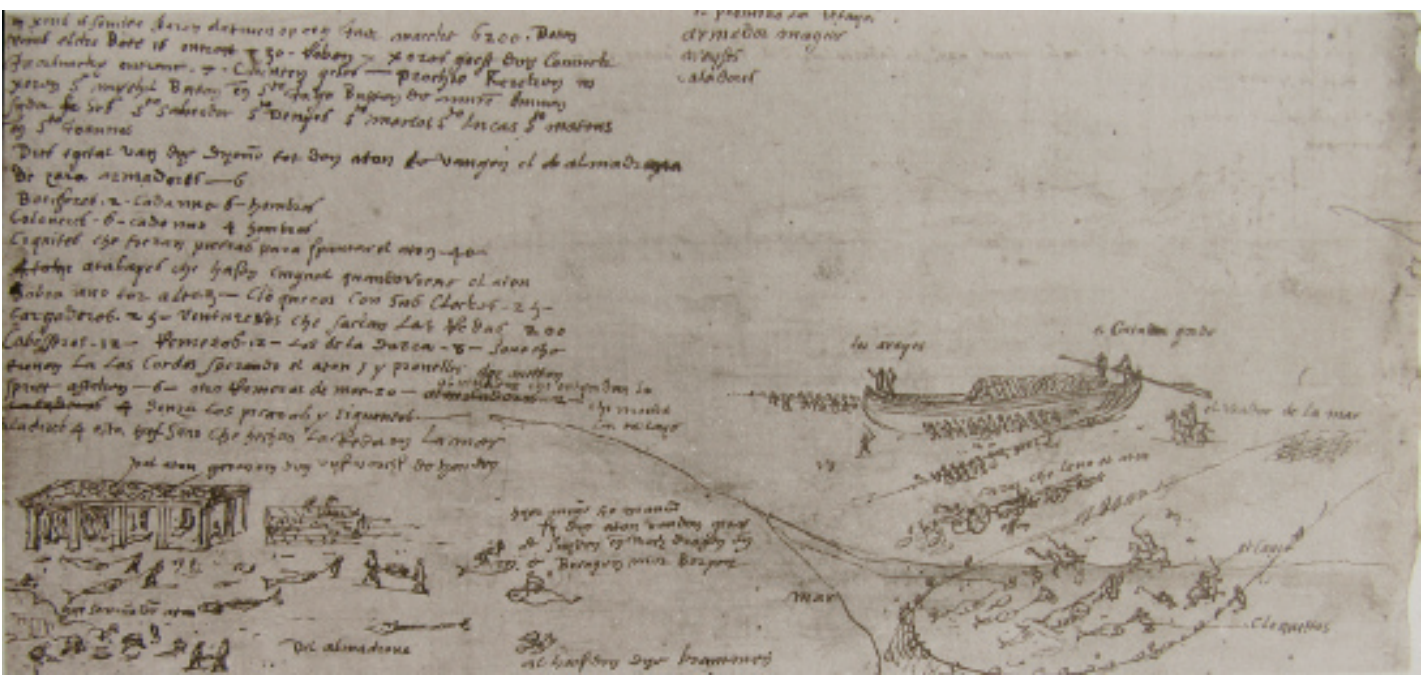

Fig. 3. Zahara de los Atunes, apuntes de la pesca y secado del atún, National-Bibliothek de Viena fol. 33 vto.

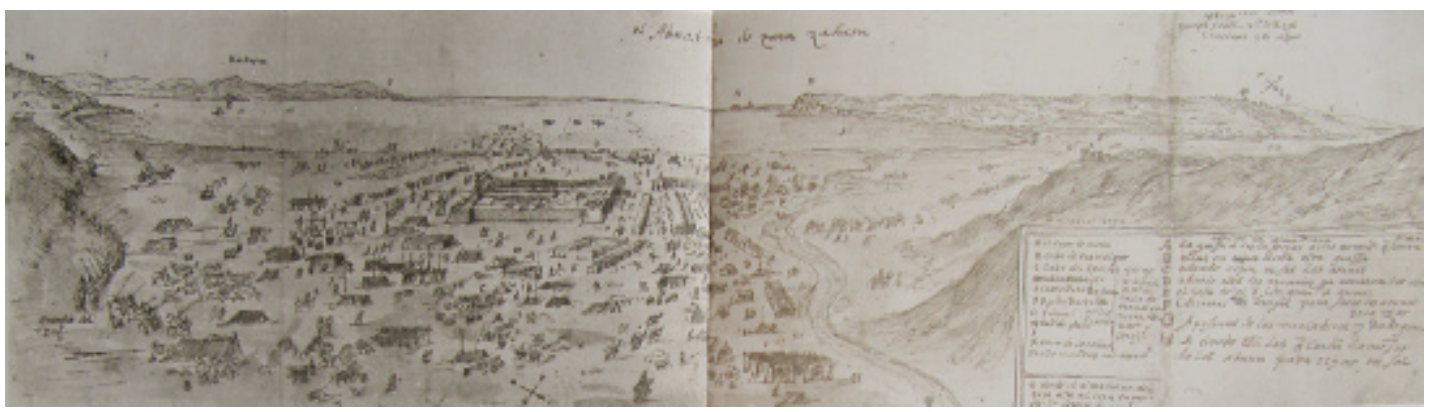

Fig. 4. Zahara de los Atunes, National-Bibliothek de Viena fol. 74.

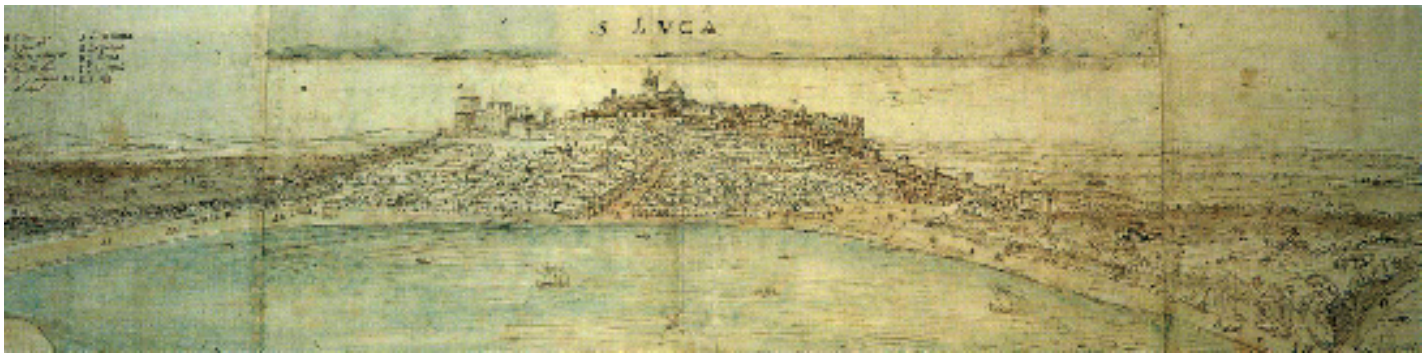

Fig. 5. Sanlúcar de Barrameda, Oxford C.III. 259.

Arch. esp. arte, LXXXVII, 346, ABRIL-JUNIO 2014, 163-170

ISSN: 0004-0428, eISSN: 1988-8511, doi: 10.3989/aearte.2014.12 
la Casa Ducal, pues ha ocupado históricamente una posición estratégica en la desembocadura del Guadalquivir, defendiendo la entrada de un río navegable que conduce hasta Sevilla, la capital del Reino de su nombre, donde se ubicaba el monopolio real del comercio americano desde la fundación de la Casa de Contratación en 1503, aunque era en las playas sanluqueñas y en su puerto donde se aprestaba la Flota de Indias, pues de allí partía y llegaba, y a la que suministraba personal de todo tipo (marinería, soldados y artilleros) artillería, y pertrechos variados (agua, productos alimenticios, cordelería...). Puede darnos idea de la Sanlúcar que dibujó Wyngaerde, la descripción que hiciera pocos años después, en 1598, Agustín de Horozco "E yo de diez i ocho años a esta parte é visto muchas i buenas casas i anchas calles en lo que el mar tenia bañado i cubierto, de manera que á sido tal su aumento que si no es el de la villa de Madrid, corte del rey, ningún otro lugar de España llega con mucho al de este ni aun en bondad i fortaleza de edificios" $"$.

En cuanto a su esplendidez, cabe decir que fue un destacado benefactor de diversas órdenes religiosas asentadas en sus posesiones territoriales y lugares donde mantenía residencia, llevando a cabo una extraordinaria política de fundaciones de nuevos conventos y una relevante actividad constructiva religiosa, militar, doméstica, fabril y de reformas urbanísticas, amén de ser muy aficionado a costear retablos, imágenes, pinturas y obras suntuarias, que dejaron, a su muerte en 1615, bastante mermadas las arcas de la $\mathrm{Casa}^{13}$. De ello dio muestras muy pronto, pues ya desde niño, viéndose con dinero en los bolsillos, compró varias figurillas, revelando un interés por la imaginería que se acrecentaría con los años. Ese gusto por las artes, se aquilató desde que su abuelo falleció y se convirtió en el heredero de tan poderosa Casa, pues su madre encargó terminar su formación al maestro Diego Dávila, "contino" del monarca, y al canónigo Alonso de Oretano, que se trasladó de Valladolid a Sanlúcar para enseñarle gramática y abrir su gusto a la literatura, con una apreciable remuneración, como resultaba vivienda, doble ración diaria de comida para él y su criado, y un sueldo de 200.000 maravedíes anuales, 3 cahíces de cebada y otros tantos de trigo, que se le aumentó en 1564 en otros 75.000 maravedíes. A lo que sumar otras personas interesantes que formaban la corte ducal, como el ilustre cosmógrafo Pedro de Medina, a su lado desde 1560 para enseñarle aquellos pasajes más destacados de la historia de su familia, adaptados a su edad, que le hizo comprender la importancia de su ilustre linaje y el papel que le correspondería representar en la sociedad del momento, que se remuneraba con 40 ducados. Por ello este autor se hacía llamar "maestro" del duque. Se ha documentado como el joven tenía aprendido el "Arte", y manejaba el diccionario de Nebrija junto a obras de Terencio, Virgilio, Cicerón y César. Otro de los que apoyaron su formación fue su ayo el comendador Gonzalo de Saavedra, que le habló de América y de la vinculación de Sanlúcar con el comercio con el Nuevo Mundo, con salario de 300.000 maravedíes al año. Además contaba con biblioteca propia, que guardaba en su cámara, y en su paso de la pubertad a la madurez, su madre le entregó 100 ducados para que los gastase como creyese conveniente ${ }^{14}$.

Ejemplo de su interés por las artes, fue la colección pictórica que mantuvo y acrecentó en su palacio sanluqueño, de la que podemos hacernos idea por la inventariada en octubre de 1588, fruto del acopio de antepasados y del suyo propio, quedando aparte la que poseía en otros palacios, como el sevillano, atesorando junto a lienzos y tablas de diversa temática, un conjunto abultado de dibujos y grabados. Cabe entresacar, en correspondencia al tema que traemos, las varias vistas de ciudades que poseyó, de ellas tres sobre lienzo con batallas libradas en Alemania y Flandes, y dos en lienzo con vistas de Argel y Amberes, a lo que

12 Horozco, 1845: 288.

13 Cruz Isidoro, 1997: 413-430; 1998: 435-459; 2001: 27-49; 2002: 357-364; 2005: 173-184; 2012: 280-287.

14 Álvarez de Toledo, 1994, t. I, pp. 23, 25-26. 
añadir dos conjuntos de muchos mapamundis y varios dibujos de castillos sobre papel. Además, el interés de la Casa ducal por los grabados ha dejado reflejo documental en su archivo ${ }^{15}$.

\section{APÉNDICE DOCUMENTAL}

1567, abril, 16, Sanlúcar de Barrameda, palacio ducal.

Libranza de D. Alonso Pérez de Guzmán, VII duque de Medina Sidonia, a Antón Van den Wyngaerde, de 50 ducados, por unas vistas de ciudades españolas que debía realizar.

Archivo Fundación Casa de Medina Sidonia leg. 2.570 fol. 127 vto.

"Por libramiento de su señoría, fecho en 16 de abril 1567, se le reciben en quenta cinquenta ducados en reales, que pago a Antonio de las Viñas, pintor de Su Magestad, por carta del señor conde de Olivares, por la (ejecu)çión y pinturas de ciertos lugares de España, que a de pintar. Mostró su carta de pago".

\section{BIBLIOGRAFÍA}

Álvarez de Toledo, Luisa Isabel: Alonso Pérez de Guzmán, General de la Invencible, 2 t. Cádiz. Universidad, 1994.

Bustamante García, Luis: "La conquista del Peñón de Vélez de la Gomera en 1564", Arte, Poder y Sociedad en la España de los siglos XV al XX, XIII Jornadas Internacionales de Historia del Arte, Madrid, noviembre, 2006, Madrid, CSIC, 2008, pp. 169-177.

Caballero Sánchez, Miguel-Ángel: "Las vistas de El Puerto de Santa María en 1567 de Antón Van den Wyngaerde: pautas interpretativas y análisis de contenidos", Revista de Historia de El Puerto n. ${ }^{\circ} 41$, El Puerto de Santa María, 2008 (2. ${ }^{\circ}$ semestre), pp. 109-147.

Cabañas Bravo, Miguel; López-Yarto Elizalde, Amelia; Rincón García, Wifredo; Arte, poder y sociedad en la España de los siglos XV a XX. Madrid, CSIC, 2008.

Cabañas Bravo, Miguel; López-Yarto Elizalde, Amelia; Rincón García, Wifredo: El arte y el viaje. Madrid, CSIC, 2011.

Cruz Isidoro, Fernando: "Luis Sánchez y Jacques de Uparque, plateros de la Casa ducal de Medina Sidonia", Laboratorio de Arte n. ${ }^{\circ}$ 10, 1997, pp. 413-430.

Cruz Isidoro, Fernando: "Francisco Juanete, pintor de cámara de la Casa ducal de Medina Sidonia (16041638)". Laboratorio de Arte n. ${ }^{\circ} 11,1998$, pp. 435-459.

Cruz Isidoro, Fernando: "Francisco de La Gándara Hermosa de Acevedo, un escultor de principios del XVII". Laboratorio de Arte n. ${ }^{\circ}$ 14, 2001, pp. 27-49.

Cruz Isidoro, Fernando: "Vasco Pereira y la serie de seis retablos dominicos para la Casa ducal de Medina Sidonia". Laboratorio de Arte n. ${ }^{\circ} 15,2002$, pp. 357-364.

Cruz Isidoro, Fernando: "La colección pictórica del palacio sanluqueño de la Casa ducal de Medina Sidonia entre los años de 1588 y 1764", Laboratorio de Arte n. ${ }^{\circ} 16,2003$, pp. 151-169.

Cruz Isidoro, Fernando: "El mecenazgo arquitectónico de la Casa ducal de Medina Sidonia entre 1559 y 1633". Laboratorio de Arte n. ${ }^{\circ}$ 18, 2005, pp. 173-184.

\footnotetext{
15 Sirva de ejemplo la libranza de 200 reales efectuada años más tarde, el 27 de abril de 1634, por su hijo el VIII duque D. Manuel, al célebre grabador Alardo de Popma. Cruz IsIDORo, 2003: 155-156.
}

Arch. esp. arte, LXXXVII, 346, ABRIL-JUNIO 2014, 163-170

ISSN: 0004-0428, eISSN: 1988-8511, doi: 10.3989/aearte.2014.12 
Cruz Isidoro, Fernando: "Juan Pedro Livadote al servicio de la condesa de Niebla: el convento de Madre de Dios (1574-1576)", Laboratorio de Arte n. ${ }^{\circ} 22,2010$, pp. 131-164.

Cruz Isidoro, Fernando: "El Convento de Santo Domingo de Sanlúcar de Barrameda: patronazgo de los Guzmanes, proceso constructivo y patrimonio artístico (1528-1605)", Laboratorio de Arte n. ${ }^{\circ} 23,2011$, pp. 79-106.

Cruz Isidoro, Fernando: “Juan Bautista Vázquez ‘el Viejo’ y Gaspar Núñez Delgado al servicio del VII duque de Medina Sidonia (1575-1576)". Archivo Español de Arte n. ${ }^{\circ} 339,2012$, pp. 280-287.

Felipe II, un monarca y su época. Un príncipe del Renacimiento, Museo del Prado octubre 1998/enero 1999, Madrid, Sociedad estatal para la conmemoración de los centenarios de Felipe II y Carlos V, 1998.

Galera I Monegal, Monserrat: Antoon van den Wijngaerde, pintor de ciudades y de hechos de armas en la Europa del Quinientos. Cartobibliografia razonada de los dibujos y grabados, y ensayo de reconstrucción documental de la obra pictórica. Barcelona, Fundación Carlos de Amberes, Instituto Cartográfico de Cataluña, 1998.

Gámiz Gordo, Antonio: "Vistas de ciudades andaluzas hasta mediados del siglo XIX", en PH Revista del Instituto Andaluz de Patrimonio Histórico n. ${ }^{\circ}$ 77, Sevilla, 2011, pp. 74-79.

Haverkamp-Begemann, Egbert: "The Spanish Views of Anton Van del Wyngaerde", en Master Drawing, vol. 3 n. ${ }^{\circ} 4,1969$, pp. 375-399.

Horozco, Agustín: Historia de la ciudad de Cádiz, Cádiz, 1845.

Ibáñez Martínez, Pedro: "Van del Wyngaerde, una vista de Belmonte y la campaña de trabajo de 1563", Archivo Español de Arte, LXXVI, n. ${ }^{\circ}$ 301, Madrid, 2003, pp. 71-77.

Kagan Richard L. (director) y otros: Ciudades del Siglo de Oro. Las Vistas Españolas de Anton Van den Wyngaerde, Madrid, Ediciones El Viso, 1988, 2008.

Velázquez Gaztelu, Juan Pedro: Catálogo de todas las personas ilustres y notables de esta ciudad de Sanlúcar de Barrameda. Desde la mayor antigüedad que se ha podido encontrar en lo escrito hasta este año de 1760, est. prelim., transcrip. y edición literaria de Fernando Cruz Isidoro, Sanlúcar de Barrameda, A.S.E.H.A, 1996.

Fecha de recepción: 18-III-2013

Fecha de aceptación: 06-IX-2013 